\title{
The use of low grade bio ethanol as fuel mixer in gasoline engine with optimization compact distillator
}

\author{
Iqbal Yamin ${ }^{1} *$, Bambang Sugiarto ${ }^{1}$, Setia Abikusna ${ }^{1}$, and Dedi Suntoro ${ }^{1}$ \\ ${ }^{1}$ Department of Mechanical Engineering, Universitas Baru UI Depok, Depok 16424 Indonesia
}

\begin{abstract}
Limited fossil energy resources need to encourage renewable energy development and energy conservation it is called green energy development. One of the alternative energy sources used are bioethanol, from low grade is converted into high grade through distillation process with distillator compact that will be used as a mixture of gasoline. Tests compact distillator consisting of evaporator Indonesia Kampus, separator, and condenser by utilizing exhaust gas to heat distillator already filled with low grade bioethanol, so the heat transfer occurs on the surface of the exhaust into the evaporator chamber. In the evaporator will transform ethanol into the vapor phase. Ethanol vapor flows into the separator, with a mechanism in it is expected that water vapor will evaporate participate separately with ethanol vapor. Ethanol vapors from this distillation will flow to the condenser and will be turned into liquid, the liquid is as high grade bioethanol would be the fuel mixing gasoline. In early studies, distillation rate was $98.5 \mathrm{ml} / \mathrm{h}$ with $67 \%$ ethanol content. Optimization compact distillator is done by adding the valve at the evaporator branch. When heat has reached $80^{\circ} \mathrm{C}$ exhaust gas flow to the evaporator chamber is closed. As a result, the heat from the evaporator can be detained and not rise significantly. Further optimization is to change the design of the separator through theoretical and empirical calculations with some assumptions based on the rule of thumb in the field of distillation, adding insulation to reduce heat leakage, as well as varying the feed volume and feed concentrate ethanol. In the end, based on the parameters of the distillation rate and ethanol concentrate, compact distillator with distances between tray $100 \mathrm{~mm}$, volume $800 \mathrm{ml}$, engine speed $5.400 \mathrm{rpm}$ can produce distillation rate of $274.3 \mathrm{ml} / \mathrm{hr}$ and ethanol concentrate of $88.97 \%$.
\end{abstract}

\section{Introduction}

The use of fossil energy is estimated if it is used continuously and not reduced, it causes oil deposit which can be discharged. To overcome this issue, we need to develop renewable alternative energy, green living, and derived from nature. One of them is biomass energy that come from organic matter and variously. Source of biomass energy could have come from plantation produce or agriculture, woods, farm or even trash. Energy of biomass can be used to produce heat, make fuel and generate electricity [6]. Biomass energy exploiting technology has been developed which consists of direct combustion and biomass conversion to fuel. The result of this conversion could include biomass gas, bio ethanol, bio diesel and liquid fuel [1].

The exploiting of bio ethanol in Indonesia as fuel is still very low. But in contrast with the bio ethanol production in low grade as kind of beverage which is consumed by particular society, whether it is in traditional or industrial scale is involved in Indonesia. Due to that case, fortunately, if production of low grade bio ethanol which is called alcohol can be exploited for positive thing such as additional fuel to vehicle. Because of that reason, it is needed

\footnotetext{
Corresponding author: iqbal.yamin@gmail.com
}

technology which accommodates low grade bio ethanol produced by people to be changed into high grade bio ethanol and the result can be applied as additional fuel to vehicle directly by distillation process [5].

S. Bambang et al [13] conducted the test by using a type of low-grade bioethanol with levels of $30 \%$. The condition of machine in testing is in static condition with a constant throttle opening. based on testing, optimization results compact distillator design produces maximum ethanol content of $96.91 \%$ by the distillation rate of $81 \mathrm{ml} /$ hour.

The purpose of this research is to study about working of compact distillator (consisting of evaporator, separator and condenser) $[3,4]$ that is the result of optimization design in previous study to low motorcycle engine speed, medium and high by varying bio ethanol feed volume, bio ethanol feed grade, and comparing performance of compact distillator to the distance between low and high separator components tray so that is expected to produce high grade bio ethanol and system which is mounted to motorcycle compactly.

\section{Experimental Details}


Evaporator part of distillatory compact apparatus is mounted directly to exhaust manifold dynamic fuel engine with the aim to exploit heat from exhaust gas for heating distillation and its installation mounted to exploit space that is in dynamic fuel engine by no changing the condition of motor physical appearance so that it is possible to do Road Test [7, 8].

To get a temperature value in compact distillator that can be measured directly by using digital thermometer infrared (noncontact infrared thermometer). Temperature that we want to feed out namely in evaporator exhaust manifold, separator intake manifold, and condenser intake manifold, and then the value that is read on infrared thermometer digital display is noted every one minute. In addition to feed out the temperature in evaporator is mounted probe apparatus which is connected to temperature control as controlling evaporator temperature. When the temperature has reached $80{ }^{\circ} \mathrm{C}$, namely ethanol vapor temperature, exhaust gas intake that is through evaporator and closed by using valve butterfly, setting open close valve butterfly is regulated by choke to handle motor, to close exhaust gas manifold in order not to pass evaporator so choke on handle is pulled down, in contrast to open it, choke on handle is pushed upward.

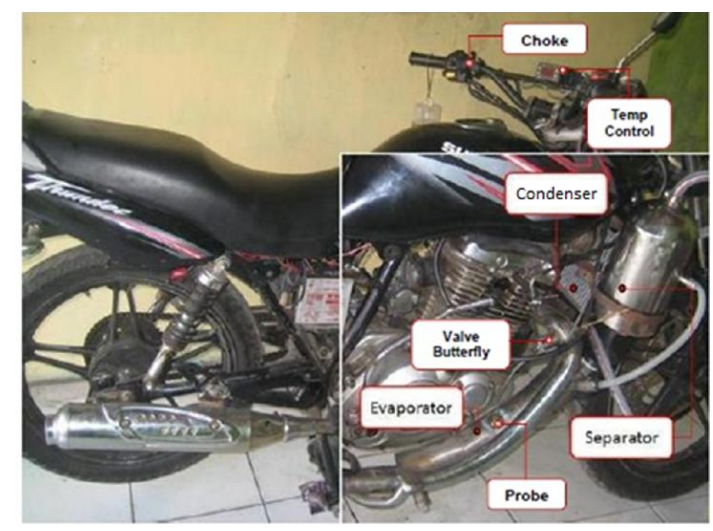

Fig. 1. Compact Distillator on Motorcycle

Firstly, low grade bio ethanol 30\% (means 30\% bio ethanol and $70 \%$ water) is delivered into evaporator. When engine works, it will produce heat exhaust gases from chamber to area through muffler. It will be exploited by evaporator to evaporate two kinds of liquid fluid that have different heating point (bio ethanol $78.32-80{ }^{\circ} \mathrm{C}$ and water $\left.100{ }^{\circ} \mathrm{C}\right)[10-12]$. In here, occurs changing phase which is formed liquid to vapour.

Fluid has lower heating point that will evaporate early and drain into separator. Separator functions to separate fluid which is not soluble each other because of the different densities. Water, its density is $(1 \mathrm{~kg} / \mathrm{l})$ than bio ethanol $(0.785 \mathrm{~kg} / \mathrm{l})$ will be under position. Nets are installed to separator that will obstruct water particles passing. So that the bio ethanol level as result of distillation is higher.

After through separator, heat vapor from bio ethanol will pass heat exchanger, which has function to remove bio ethanol heat by vapor phase, so bio ethanol phase returns to liquid phase. After that, liquid bio ethanol will be retained and used again as mixer fuel and gasoline.

Gate valve is used to control heat exhaust gas from muffler. Gate valve is installed to manifold into evaporator and bypass manifold. In normal condition, gate valve in bypass manifold will close but evaporator manifold will open.

Yet, when thermocouple is installed to evaporator, it sends signal to temperature control which is condition of temperature in evaporator has reached bio ethanol heating point, so tap on gate valve will be rotated manually and heat flow will pass through bypass, however gate valve on evaporator manifold will close. Then manifold that connects between evaporator to separator and from separator to heat exchanger, is used isolated copper pipe, it means that to prevent convection removing caloric.

In previous study, it has done design optimize by redesigning one of compact distillator components, namely separator. Design is done through theoretical calculation and empiric by using assumption based on rule of thumb in distillation. In evaporator (re boiler) is set temperature equal to $369 \mathrm{~K}$ whereas in condenser is set temperature equal to $355 \mathrm{~K}$, refers to heating-point and process of condensing vapor-point. Reflux factor (R/Rmin) effects number of actual phase needed. By considering limitation of dimension to motorcycle, decided reflux factor equal to 4 so got acquisition 9 levels in column [9].

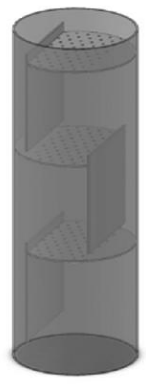

Fig. 2. New Separator Design

Separator in compact distillator is 1.5 inches stainless steel pipe based on standardization of ANSI/ASME B36.10M-1995 which has outside diameter $48.3 \mathrm{~mm}$, thickness of wall $3.68 \mathrm{~mm}$ and inside diameter $40.94 \mathrm{~mm}$. Sort of tray in separator is sieve tray. Thickness of metal sheet tray that is based on calculation is $1 \mathrm{~mm}$ and amount of pit for each tray is 128 pieces for diameter $1 \mathrm{~mm}$. Separator is made of stainless steel $316 \mathrm{~L}$ in order to corrosion resistance. In this study, it will be made two separators. First separator has tray spacing about $100 \mathrm{~mm}$ while second separator has tray spacing about $70 \mathrm{~mm}$. Based on design calculation, an optimal tray spacing is about 100 $\mathrm{mm}$ but available space in motorcycle to install separator has tray spacing about $70 \mathrm{~mm}$. Hoped that the result of separator test for tray spacing is $70 \mathrm{~mm}$ and not have significant result with tray spacing $100 \mathrm{~mm}$, so compact distillator has high performance but still compact.

Corresponding author: iqbal.yamin@gmail.com 
In here, do retrieving data equal to 4 experiments namely:

1. Gasoline and distillate alcohol $30 \%$ at low speed $(<2200$ Rpm) by having less leackage at connector between separator to heat exchanger.

2. Gasoline and distillate alcohol $30 \%$ at low speed without leackage in compact distillator apparatus.

3. Gasoline and distillate alcohol $30 \%$ at Fluctuated speed without leackage in compact distillator apparatus.

4. Gasoline and distillate alcohol $30 \%$ at high speed $(>6000 \mathrm{Rpm})$ without leackage in compact distillator apparatus.

Retrieving four datas above is done by using equal test media, namely motorcycle suzuki thunder $125 \mathrm{cc}$ with compact distillator that is installed in header pipe to exploit heat from motorcycle exhaust gas. Retrival is done when test appatus temperature is in equal condition, namely at $31^{\circ} \mathrm{C}$ until $32^{\circ} \mathrm{C}$ to take apropriate and valid datas.

Retrieving data in compact distillator apparatus that occurs leackage is done to feedd out influence of leackage distillator apparatus to distillation rate and influence to produced ethanol grade. Retrieving data is done by using gasoline to test engine media by distilating alcohol $30 \%$ in compact distillator.

\section{Result and Discussion}

Influence of exploiting exhaust gas to heat distillatory is based on fuel consumption and emission gas. Experiment was done to gasoline Otto engine (motorcycle Suzuki Thunder $125 \mathrm{cc}$ ) in variety torque by exploiting exhaust gas to distillator heater

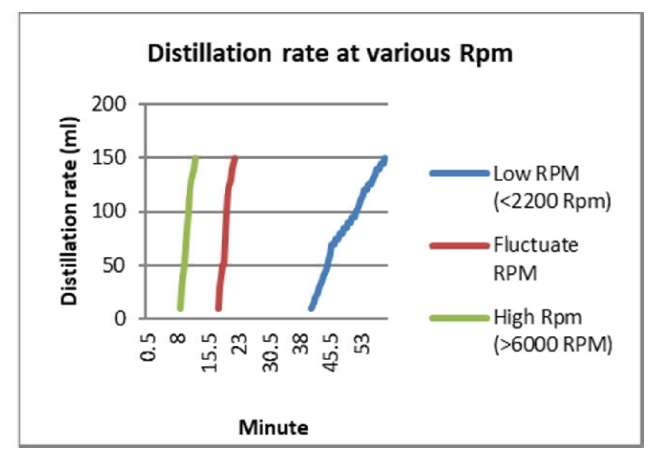

Fig. 3. Distillation Rate at Various Rpm without Temperature Control

From chart above can be seen that high engine speed ( $>$ $6000 \mathrm{rpm}$ ) is able to produce the fastest distillation rate and in low speed refers to need long duration to produce distillation. From obtained data, duration is needed to distillate low grade ethanol to be high grade ethanol and distillation volume rate is comparable undeviating to engine speed that is used to test compact distillator apparatus. It shows that heat exhaust gas is used as distillation energy source that is influenced by engine speed. The higher engine speed, the higher heat in muffler and the effect of evaporating distillation low grade ethanol in evaporator is higher. Increasing of the highest temperature from exhaust gas is unexpected, because it will influence faster evaporating distillation and water grade in distillation will also evaporate and then it will influence to high grade ethanol produced.

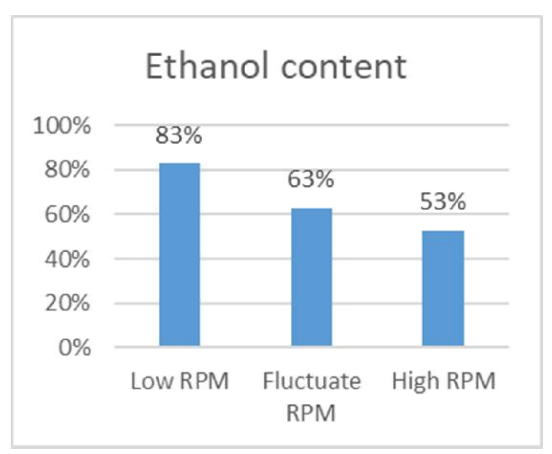

Fig. 4. Ethanol Content at Various Rpm

From chart above, it is known that alcohol concentration mean of every speed, whereas the highest alcohol concentration is reached by low speed with percentage equals to $83 \%$, in low speed produces higher alcohol concentration because of water low speed that is distillated its phase unchanging thoroughly, whereas alcohol has changed its phase so most of result in compact distilator is alcohol. It is due to exhaust gas that is resulted in low speed relative constant so heat that is generated in muffler indicating increase slowly then it will very influence to unit that will be distillated to compact distillator. Whereas in fluctuate speed and high speed is in relative low grade due to distillated water has changed its phase and distillated with alcohol so it produces lower level. It caused by increasing of temperature to significant exhaust gas because of combustion in combustion chamber. Because there is no temperature setting toward header pipe that is used as compact distillator energy source so all heats will be used to heat distillate in evaporator compact distillator.

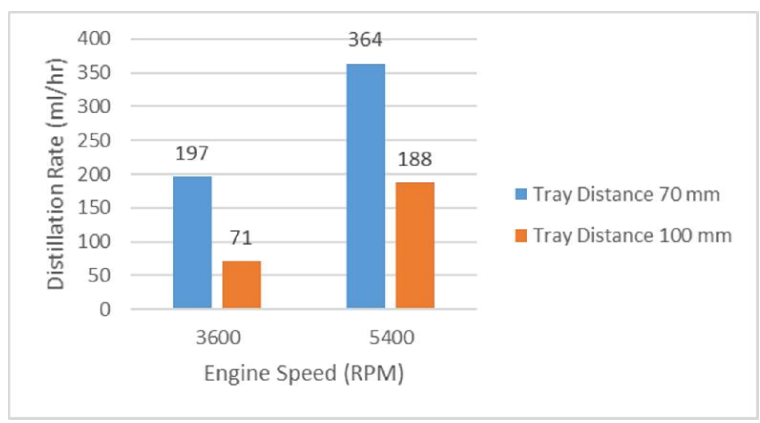

Fig. 5. Comparation Distillation Rate between Tray $70 \mathrm{~mm}$ and $100 \mathrm{~mm}$ before Valve Closed

\footnotetext{
Corresponding author: iqbal.yamin@gmail.com
} 


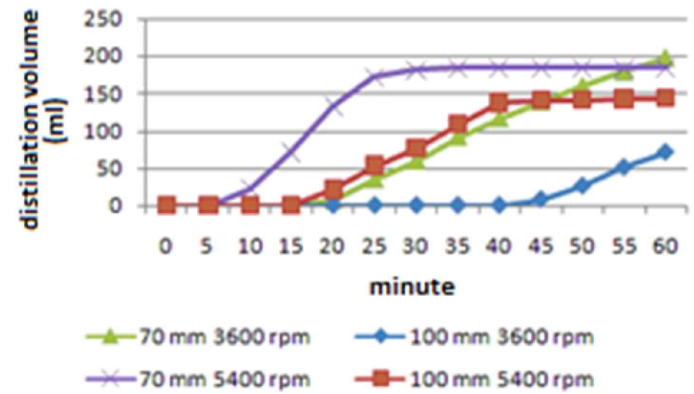

Fig. 6. Comparation Total Rate of Distillation between Tray 70 $\mathrm{mm}$ and $100 \mathrm{~mm}$

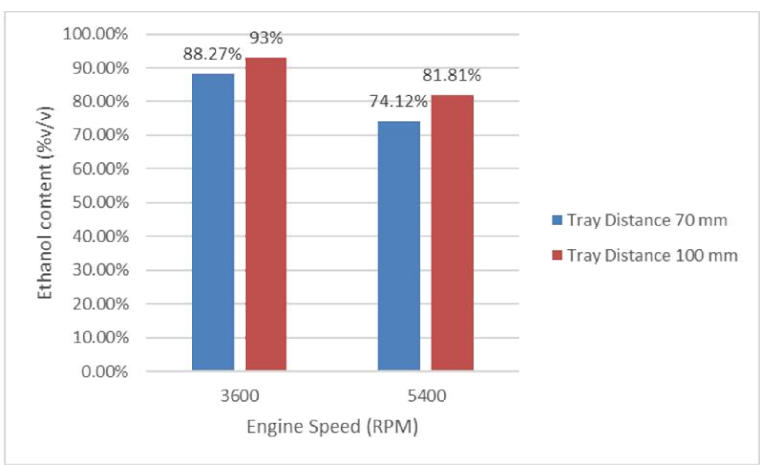

Fig. 7. Comparation Ethanol Distillate between Tray $70 \mathrm{~mm}$ and $100 \mathrm{~mm}$

Figure 5 shows distillation rate before exhaust gas valve closed whereas in figure 6 totally distillation rate for one hour in experiment by closing valve. It causes distillation rate stops so distillate volume is still seen in figure 6 . Based on figure 5 and 6 , distillation rate in separator $\mathrm{A}$ is faster than separator B. Based on engine speed, distilltation rate in higher engine speed, it works faster than lower engine speed. Maximum distillation rate by closing valve is 197 $\mathrm{ml} /$ hour in separator A test and engine speed $3600 \mathrm{rpm}$. But distillation rate before closing valve occurs in separator A test maximumly and engine speed $5400 \mathrm{rpm}$ equal to 364 $\mathrm{ml} /$ hour. Separator B produces higher grade ethanol distillate than separator A. Higher engine speed decreases ethanol distillatel grade whether in separator A or separator $\mathrm{B}$ as seen by figure 7 .

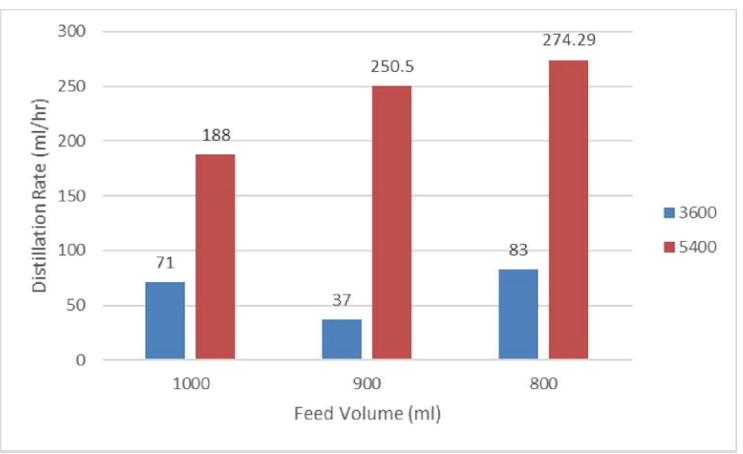

Fig. 8. Comparation Distillation Rate before Valve Closed with Various Feed Volume

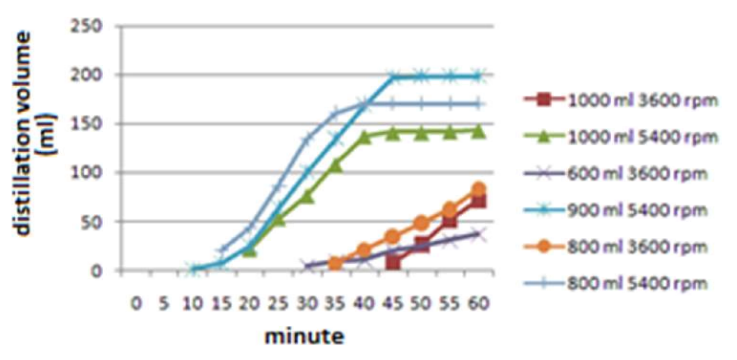

Fig. 9. Comparation Total Rate of Distillation with Various Feed Volume

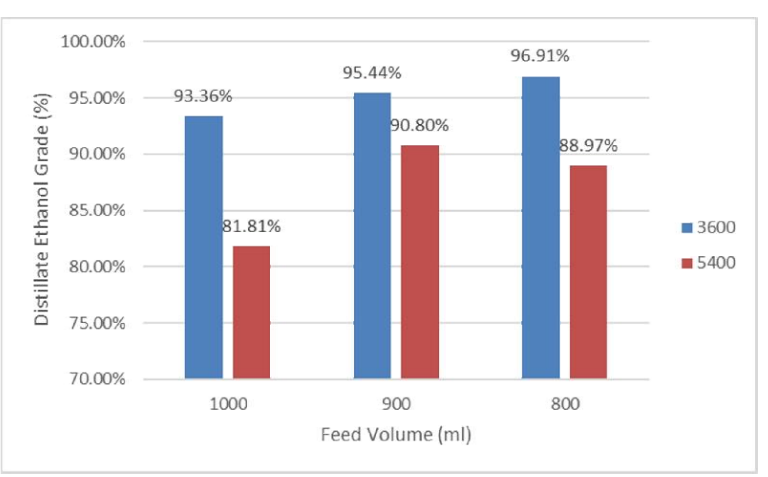

Fig. 10. Comparation Ethanol Distillate with Various Feed Volume

Distillation rate increases to the less feed volume is seen in figure 8 and 9 . When number of feed volume is less so temperature is heat faster so bio ethanol in evaporator will evaporate faster. In engine speed $5400 \mathrm{rpm}$, distillation rate is also determined by timing of open close valve so distillation rate is fluctuative . Distillate ethanol grade is shown in figure 10 whereas the less feed volume, the higher ethanol grade.

\section{Conclusion}

With shorter tray spacing, compact distillator produces lower grade alcohol but distillation rate is higher. The lower feed volume produced higher grade alcohol, distillation speed is higher but thermal efficiency is lower. Based on distillation rate parameter and alcohol grade produced, compact distillator with tray spacing $100 \mathrm{~mm}$, volume 800 $\mathrm{ml}$, engine speed $5400 \mathrm{rpm}$ produces the best work namely distillation rate $274.3 \mathrm{ml} /$ hour and alcohol grade $88.97 \%$.

The authors would like to thank PITTA UI for providing the grant in this research so that it can be completed well.

\section{References}

[1] Pulkrabek, W. Willard, Engineering fundamentals of the internal combustion engine, New Jersey: Prentice Hall, (1997)

\footnotetext{
Corresponding author:iqbal.yamin@gmail.com
} 
[2] Y.A. Cengel, M.A. Boles, Thermodynamics an engineering approach (5th ed.), McGraw-Hill, (2006)

[3] H.Z. Kister, Distillation design, McGraw-Hill, (1992)

[4] M.F. Doherty, M.F. Malone, Conceptual design of distillation systems (vol 1), McGraw-Hill, (2001)

[5] E.W.Z. Aguilar, J.R.S. Moreira, Thermal design of a tray type distillation column of an ammonia/water absorption refrigeration cycle, International Journal of Applied Thermal Engineering, (2011)

[6] R.E. Treybal, Mass-transfer operations ( $3^{\text {rd }}$ ed.), Singapore: McGraw-Hill, (1981)

[7] J.P. Liu, et al., Comparison and analysis of engine exhaust gas energy recovery potential through various bottom cycles, Applied Thermal Engineering, 50(1): p. 1219-1234, (2013)

[8] R. Saidur, et al., Technologies to recover exhaust heat from internal combustion engines Renewable and Sustainable, Energy Reviews, 16(8): p. 56495659, (2012)

[9] S. Elgue, et al., Dynamic models for start-up operations of batch distillation columns with experimental validation, Computers \& Chemical Engineering, 28(12): p. 2735-2747, (2004)

[10] R.C Costa, J.R. Sodré, Compression ratio effects on an ethanol/gasoline fuelled engine performance, Applied Thermal Engineering, 31(2-3): p. 278-283, (2011)

[11] T.C.C.d. Melo, et al., Hydrous ethanol-gasoline blends - Combustion and emission investigations on a Flex-Fuel engine Fuel, 97(0): p. 796-804, (2012)

[12] A. Kyriakides, et al., Evaluation of gasolineethanol-water ternary mixtures used as a fuel for an Otto engine, Fuel, 108(0): p. 208-215, (2013)

[13] S. Bambang, et al., Optimization of Low-Grade Bioethanol Compact Distillator Using Waste Heat Motorcycle, (2015)

Corresponding author:iqbal.yamin@gmail.com 